\title{
INFLUENCE OF MOTOR ABILITIES ON LEARNING OF ALPINE SKI TECHNIQUE
}

\author{
Vjekoslav Cigrovski ${ }^{1}$, Igor Božić ${ }^{2}$, and Nikola Prlenda ${ }^{1}$ \\ ${ }^{1}$ Faculty of kinesiology, University of Zagreb, Croatia \\ ${ }^{2}$ Faculty of Physical Education and Sports, University of Banja Luka, \\ Bosnia and Herzegovina
}

\section{SUMMARY}

The research determined influence of motor abilities on alpine ski learning. Moreover, the aim was also to estimate the contribution of some morphological characteristics to acquisition of ski knowledge. At the beginning of the study, participants were tested by tests evaluating balance, agility, explosive and static strength, movement frequency and flexibility. After evaluation of motor abilities, basic morphological characteristics were noted and then participants entered a seven days alpine ski course. Acquired alpine ski knowledge was assessed through demonstration of seven elements of alpine ski technique, by five independent judges. Data analysis showed positive influence of agility on all tested elements of alpine ski technique (traversing, $\beta=.38$; $\beta=.26$; uphill turn, $\beta=.33$; $\beta=.23$; basic turn, $\beta=.18$; parallel turn, $\beta=.32$; short turn, $\beta=.34$ ). Subjects' results in squat endurance test assessing the static leg strength contribute to learning uphill turn $(\beta=.19)$, basic turn $(\beta=.35)$ and parallel turn $(\beta=.27)$. Test used to measure balance (single leg balance test) significantly influences learning of basic elements of alpine ski technique (traversing right, $\beta=.23$; traversing left, $\beta=.28$; uphill turn to the left, $\beta=$.24). Body height has a negative effect on alpine ski learning $(\beta=-0.5)$, indicating that taller ski beginners tend to have more difficulties during alpine ski learning than shorter alpine ski beginners. According to our results, agility, static leg strength and balance are the motor abilities with the greatest influence on beginners' alpine ski learning

Key Words: alpine skiing, learning, motor abilities, morphological characteristics.

\section{INTRODUCTION}

Children and young people less frequently spend their free time doing some physical activity in a natural environment, so it is recorded that the number of obese people among this population was increasing during the past years (Benson, Torode, \& Fiatarone Singh, 2008; Grung, Krause, Siewers, Rieckert, \& Muller, 2000; Laguna, Ruiz, Lara, \& Aznar, 2012). Obvious lack of physical activity influences the whole body composition, and reflects negatively on growth and development (Högström, Pietilä, Nordström, \& Nordström, 2012). Motor abilities are often neglected or developed poorly in children, and their level influences significantly better or worse technical performance in each sport, so as in skiing. Therefore, there is an increasing social necessity for taking care of young people's physical activity, which will influence the development of motor abilities (Cleland et al., 2008). Alpine skiing is extremely mass sport at recreation level (Horterer, 2005) and a large number of families go skiing during the winter. Aim of this study is to try to answer the question on helping ski beginners to learn skiing easily. Fear of injury, caused by skiing speed contributes to loss of proportion of ski beginners in further alpine ski learning, often loss of the balance or high ski lifts contribute additionally. Moreover, some skiers give up further ski learning because of the previous inadequate fitness motor preparation. In alpine skiing a person moves in a specific way which occurs rarely in an everyday life, so that is the reason why proper fitness preparation 
of a beginner skier is harder. It is known that in alpine skiing some motor abilities are used more than the other (Dolenec \& Žvan, 2001; Emeterio \& Gonzales-Badillo, 2010; Neumayr et al., 2003). The studies also showed that the same motor abilities in the same ratio do not influence equally the competitor skiers' sports results and skiing learning efficiency in recreational skiers (Cigrovski, Matković, \& Matković, 2008a, 2008b; Cigrovski, Bilić, Prlenda, \& Martinčević, 2010; Gross et al., 2010; Maffiuletti, Jordan, Spring, Impellizzeri, \& Bizzini, 2009; Oreb, Vlašić, Cigrovski, Prlenda, \& Radman, 2011). Having in mind the proof that certain motor abilities are differently employed in competitive skiers and recreational skiers, this study's aim is to determine which motor abilities contribute to learning of elements of alpine ski technique in ski beginners. The study will also try to determine the influence of some morphological characteristics on efficiency of learning alpine skiing.

\section{METHODS}

86 subjects participated in this study and their age was $22.76 \pm 1.15$. All the subjects were male and beginners without any previous experience in alpine skiing. For this study 17 tests were chosen in order to assess subjects' motor abilities. All the applied tests for motor abilities assessment were carried out according to standard procedure for measurement and they were chosen because of their good metric characteristics (Bosco, 1997; Reid, Johnson, Kipp, Albert, \& White, 1997). The following tests were used: side agility with step and close (MAGKUS), frontal agility (MAG9NN), vertical squat jump (MESSJ), vertical jump with preparation (MESCM), standing long jump (MESSDM), throwing the medicine ball from supine position (MESBML3), leg taping - 15 seconds (MFRTAN), "cating" - 15 seconds (MFRCAT), "sit and reach" (MFLSAR), longitudinal left leg balance (MRU10L), longitudinal right leg balance (MRU10D), diagonal left leg balance (MRP10L), diagonal right leg balance (MRP10D), 20m running (MES20M), and "hexagon" (MAGHEX). Morphological characteristics followed in this study are measured according to instructions and regulations of International Biological Program (IBP). This program consists of 39 measures (Mišigoj-Duraković, 2008), and the ones used in this study are: body height (HEIGHT), body mass (MASS), body fat percentage (\% FAT), right thigh girth (OPSNATD). Alpine skiing learning process has lasted for 7 days for all the subjects. During these 7 days, the subjects had the same conditions related to a number of subjects in each skiing group
(10), a number of hours spent on learning every day (4), amount of exercising every day (2), quality and adequacy of ski equipment, ski instructor and skiing ground adequacy. After learning process was completed, all the subjects were joined in one group, and in alphabetical order they presented 7 previously learned skiing technique elements to independent judges. On the basis of marks given for the demonstrations of traversing left (KSL), traversing right (KSD), left uphill turn (ZKBL), right uphill turn (ZKBD), basic turn $(\mathrm{OZ})$, parallel turn (PZ), and short turn (V), acquired skiing knowledge of every subject was evaluated. Marks for subjects' knowledge ranged from 1 to 5 , where 1 represents the poor and 5 represents the superb skiing knowledge. Since the study's results depend significantly on skiing instructors and judges, they were very carefully chosen. Every single instructor and judge included in this study got detailed instructions on a method of beginner skiers teaching and a method and criteria for evaluation. Standard procedure for measurement for evaluation of skiing knowledge was carried out while collecting data (Cigrovski et al., 2008a, 2008b). Data in this study were processed by regression analysis with the aim to determine the influence of the predictor set of tests for assessment of motor abilities and determined morphological abilities on the level of skiing knowledge. Factor analysis was used for the entire skiing knowledge determination. Collected data were analyzed by statistics package "Statistica 8.0". The obtained results were considered statistically significant with $p$ $<.05$.

\section{RESULTS AND DISCUSSION}

In Tables from 1 to 7 is shown the contribution of test results obtained during assessment of developed motor abilities and determined morphological characteristics of the subjects to learning of alpine skiing technique elements: traversing right and left, right and left uphill turn, basic turn, parallel turn and short turn.

Four tests for motor abilities assessment selected by regression analysis statistically significantly contribute to learning of traversing. These four selected tests explain $23 \%$, i.e. $20 \%$ of common variability while learning traversing $\left(R^{2}=.23 ; R^{2}=.20\right)$, and the greatest single influence on traversing learning has the subject's result in hexagon $(\beta=.38 ; \beta=.26)$. Since the traversing left and right elements are performed statically, without additional movement of a skier during the performance, one can expect that subject' results in tests for static balance assessment 
TABLE 1

Regression analysis results $\left(\mathrm{R}=.45 ; \mathrm{R}^{2}=.25 ; p=.00\right)$ between tests for assessment of subjects' motor abilities and determined morphological characteristics, and success in demonstration of skïng technique elements for traversing left.

\begin{tabular}{lcccc}
\hline & B & \multicolumn{1}{l}{ SE } & \multicolumn{1}{l}{$\beta$} \\
\hline MFRCAT & -.08 & .03 & -.31 &. $\mathbf{0 1}$ \\
\hline MRSPT6 & .02 & .01 & .20 & .07 \\
\hline MRU10L & .01 & .00 & .23 & $\mathbf{. 0 3}$ \\
\hline MAGHEX & .22 & .06 & .38 & $\mathbf{. 0 0}$ \\
\hline
\end{tabular}

Legend: MFRCAT - "Cating" - 15 seconds; MRSPT6 - Body raising in 60 seconds;

MRU10L - Longitudinal left leg balance; MAGHEX - "Hexagon"; B - Partial regression non-standardized coefficient; SE - Standard error in B coefficient assessment; $\beta$ - Standardized (partial) regression coefficient; $\mathbf{p}$ - Probibality.

TABLE 2

Regression analysis results $\left(\mathrm{R}=.57 ; \mathrm{R}^{2}=.32 ; p=.00\right)$ of tests for assessment of subjects' motor bilities and determined morphological characteristics, and success in demonstration of skiing technique elements for right uphill turn.

\begin{tabular}{lcccc}
\hline & \multicolumn{1}{l}{$\mathrm{B}$} & \multicolumn{1}{l}{$S E$} & $\beta$ & \multicolumn{1}{l}{$p$} \\
\hline MFRCAT & -.07 & .03 & -.25 & $\mathbf{. 0 3}$ \\
\hline MRSPT6 & .03 & .01 & .30 & $\mathbf{. 0 1}$ \\
\hline MRU10L & .01 & .00 & .28 & $\mathbf{. 0 1}$ \\
\hline MAGHEX & .16 & .07 & .26 & $\mathbf{. 0 2}$ \\
\hline
\end{tabular}

Legend: MFRCAT - "Cating" - 15 seconds; MRSPT6 - Body raising in 60 seconds;

MRU10L - Longitudinal left leg balance; MAGHEX - "Hexagon"; B - Partial regression non-standardized coefficient; SE - Standard error in B coefficient assessment); $\beta$ - Standardized (partial) regression coefficient; $\mathbf{p}$ - Probibality.

TABLE 3

Regression analysis results $\left(\mathrm{R}=.57 ; \mathrm{R}^{2}=.32 ; p=.00\right)$ of tests for assessment of subjects' motor bilities and determined morphological characteristics, and success in demonstration of skiing technique elements for right uphill turn.

\begin{tabular}{lrrrr}
\hline & \multicolumn{1}{c}{$\mathrm{B}$} & \multicolumn{1}{l}{ SE } & \multicolumn{1}{c}{$\beta$} \\
\hline MAGKUS & .36 & .13 & .26 & $\mathbf{. 0 1}$ \\
\hline MFRTAN & -.09 & .04 & -.24 & $\mathbf{. 0 3}$ \\
\hline MRSPT6 & .02 & .01 & .18 & .07 \\
\hline MES20M & .63 & .37 & .16 & $\mathbf{. 0 1}$ \\
\hline MAGHEX & .19 & .06 & .33 & $\mathbf{. 0 0}$ \\
\hline HEIGHT & -.05 & .02 & -.50 & $\mathbf{. 0 0}$ \\
\hline MASS & .03 & .01 & .34 & $\mathbf{. 0 2}$ \\
\hline
\end{tabular}

Legend: MAGKUS - Side agility with step and close; MFRTAN - Leg taping - 15 seconds; MRSPT6 - Body raising in 60 seconds; MES20M - Running 20 m; MAGHEX -

"Hexagon"; HEIGHT - Body height; MASS - Body mass; B - Partial regression non-standardized coefficient; SE - Standard error in B coefficient assessment; $\beta$ - Standardized (partial) regression coefficient; $\mathbf{p}$ - Probibality. 


\section{TABLE 4}

Regression analysis results $\left(\mathrm{R}=.43 ; \mathrm{R}^{2}=.19 ; \mathrm{p}=.00\right)$ of tests for assessment of subjects' motor abilities and determined morphological characteristics, and success in demonstration of skïng technique elements for left uphill turn.

\begin{tabular}{lcccc}
\hline & B & \multicolumn{1}{l}{$S E$} & $\beta$ & \multicolumn{1}{l}{$p$} \\
\hline MRSPT6 & .02 & .01 & .21 & .06 \\
\hline MSSIC & .00 & .00 & .19 & $\mathbf{. 0 5}$ \\
\hline MRU10L & .01 & .00 & .24 & $\mathbf{. 0 3}$ \\
\hline MAGHEX & .13 & .06 & .23 & $\mathbf{. 0 3}$ \\
\hline
\end{tabular}

Legend: MRSPT6 - Body raising in 60 seconds; MSSIC - Squat endurance; MRU10L -

Longitudinal left leg balance; MAGHEX - "Hexagon"; B - Partial regression non-standardized coefficient; SE - Standard error in B coefficient assessment; $\beta$ - Standardized (partial) regression coefficient; $\mathbf{p}$ - Probibality.

\section{TABLE 5}

Regression analysis results $\left(\mathrm{R}=.47 ; \mathrm{R}^{2}=.22 ; p=.00\right)$ of tests for assessment of subjects' motor abilities and success in demonstration of skiing technique elements for basic turn.

\begin{tabular}{lrrrr}
\hline & \multicolumn{1}{l}{ B } & \multicolumn{1}{l}{ SE } & \multicolumn{1}{l}{$\beta$} \\
\hline MSSIC & .01 & .00 & .35 & $\mathbf{. 0 0}$ \\
\hline MES20M & -.88 & .48 & -.18 & .07 \\
\hline MAGHEX & .12 & .07 & .18 & .09 \\
\hline
\end{tabular}

Legend: MSSIC - Squat endurance; MES20M - Running 20 m; MAGHEX - "Hexagon";

B - Partial regression non-standardized coefficient; SE - Standard error in B coefficient assessment; $\beta$ - Standardized (partial) regression coefficient; $\mathbf{p}$ - Probibality.

\section{TABLE 6}

Regression analysis results $\left(\mathrm{R}=.47 ; \mathrm{R}^{2}=.22 ; p=0,00\right)$ of tests for assessment of subjects' motor abilities and success in demonstration of skiing technique elements for parallel turn.

\begin{tabular}{lcccc}
\hline & \multicolumn{1}{l}{ B } & \multicolumn{1}{l}{ SE } & \multicolumn{1}{l}{$\beta$} & \multicolumn{1}{l}{$p$} \\
\hline MAG9NN & .34 & .16 & .22 & $\mathbf{. 0 3}$ \\
\hline MSSIC & .00 & .00 & .27 & $\mathbf{. 0 1}$ \\
\hline MAGHEX & .20 & .07 & .32 & $\mathbf{. 0 0}$ \\
\hline
\end{tabular}

Legend: MAG9NN - Frontal agility; MSSIC - Squat endurance; MAGHEX - "Hexagon"; B - Partial regression non-standardized coefficient; SE - Standard error in B coefficient assessment; $\boldsymbol{\beta}$ - Standardized (partial) regression coefficient; $\mathbf{p}$ - Probibality.

influence significantly the learning process $(\beta=.23$; $\beta=.28)$. Correlation of balance with success during ski beginners' learning of basic elements of alpine ski technique was also noted in studies carried out by Malliou et al. (2004), whose experimental group had balance improvement trainings besides learning of basic alpine skiing technique. In his study, Kostelić (2005) also emphasizes that balance can probably make an important difference between those who will learn to ski faster than the ones who will acquire the skiing technique somewhat slower.

Of all the used tests for assessment of motor abilities, the biggest influence on acquiring of traversing elements had tests for agility assessment (side agility with step and close $\beta=.26$ and hexagon $\beta=$ $.33 ; \beta=.23)$. Except the tests for assessment of motor abilities in right uphill turn, body height and mass are selected as morphological measures which 


\section{TABLE 7}

Regression analysis results $\left(\mathrm{R}=.52 ; \mathrm{R}^{2}=.27 ; p=.00\right)$ of tests for assessment of subjects' motor abilities and determined morphological characteristics, and success in demonstration of skiing technique elements for short turn.

\begin{tabular}{lrrrr}
\hline & \multicolumn{1}{l}{$\mathrm{B}$} & \multicolumn{2}{l}{ SE } & \multicolumn{2}{l}{$p$} \\
\hline MAGKUS & .43 & .17 & .26 & $\mathbf{. 0 2}$ \\
\hline MAG9NN & .44 & .18 & .26 & $\mathbf{. 0 2}$ \\
\hline MAGHEX & .24 & .07 & .34 & $\mathbf{. 0 0}$ \\
\hline HEIGHT & -.03 & .01 & -.24 & $\mathbf{. 0 4}$ \\
\hline \%FAT & -.08 & .04 & -.34 & $\mathbf{. 0 3}$ \\
\hline OPSNATD & .07 & .04 & .33 & $\mathbf{. 0 5}$ \\
\hline
\end{tabular}

Legend: MAGKUS - Side agility with step and close; MAG9NN - Frontal agility;

MAGHEX - "Hexagon"; HEIGHT - Body heihgt; \%FAT - Body fat percentage;

OPSNATD - Right thigh scope; B - Partial regression non-standardized coefficient;

SE - Standard error in B coefficient assessment; $\beta$ - Standardized (partial) regression coefficient; $\mathbf{p}$ - Probibality.

TABLE 8

Factor analysis results.

\begin{tabular}{ccrc}
\hline $\begin{array}{c}\text { Components } \\
\text { (Factors) }\end{array}$ & $\begin{array}{c}\text { Characteristic } \\
\text { value }\end{array}$ & $\begin{array}{c}\% \\
\text { variance }\end{array}$ & $\begin{array}{c}\text { Cumulative } \\
\%\end{array}$ \\
\hline 1 & 4.36 & 62.26 & 62.26 \\
\hline 2 & .91 & 13.00 & 75.26 \\
\hline 3 & .63 & 8.96 & 84.22 \\
\hline 4 & .47 & 6.67 & 90.89 \\
\hline 5 & .26 & 3.71 & 94.60 \\
\hline 6 & .21 & 2.95 & 97.55 \\
\hline 7 & .17 & 2.45 & 100.00 \\
\hline
\end{tabular}

\section{TABLE 9}

Regression analysis results $\left(\mathrm{R}=.48 ; \mathrm{R}^{2}=.23 ; p=.00\right)$ of tests for assessment of subjects' motor abilities and acquired alpine ski knowledge.

\begin{tabular}{lcccc}
\hline & B & SE & \multicolumn{1}{l}{$\beta$} & \multicolumn{1}{l}{$p$} \\
\hline MSSIC & .00 & .00 & .21 & $\mathbf{. 0 4}$ \\
\hline MRU10L & .01 & .00 & .21 & $\mathbf{. 0 4}$ \\
\hline MAGHEX & .29 & .08 & .35 & $\mathbf{. 0 0}$ \\
\hline
\end{tabular}

Legend: MSSIC - Squat endurance; MRU10L - Longitudinal left leg balance; MAGHEX

- "Hexagon"; B - Partial regression non-standardized coefficient; SE - Standard error in B coefficient assessment; $\beta$ - Standardized (partial) regression coefficient; p - Probibality.

influence significantly the level of acquired knowledge related to this element. Having in mind that the obtained body height result has a minus sign, we can assume it reversely influences the speed of skiing technique acquiring. The obtained results can be explained by the fact that in higher skiers the body's centre of gravity is further from snow field than in shorter skiers, therefore it is easier for them to disrupt the balance and harder to get it back while moving downhill. Except the negative influence of skier's body height on balance, it also influences coordination negatively, so it means that higher skiers learn 
alpine skiing harder than the shorter ones (Dolenc \& Žvan, 2001). Unlike the body height, skier's body mass has a positive influence on level of acquired knowledge related to uphill turn. Proved positive contribution of body mass can be explained by necessary continuous body pressure of a skier on outer ski while performing uphill turn. We can expect that the skiers with greater body mass will make the necessary body pressure over the skis to the snow field more easily. An important rule of properly performed turn is that a skier must transfer his body mass mostly or completely to the outer ski (Matković, Ferenčak, \& Žvan, 2004), and uphill turn is one of the first turns which a ski beginner learns. Therefore, it is logical to have a positive contribution of test results for longitudinal left leg balance on a balance bench while learning uphill turn.

Basic turn, parallel turn and short turn are skiing technique elements in which a skier associates more turns continuously, so in their performance leg muscles are much more engaged in comparison to traversing and uphill turn which are only performed to the left or right side. Three selected tests for subjects' motor abilities assessment explain $22 \%$ of common variability while learning basic turn $\left(R^{2}=.22\right)$, and the greatest single influence on learning basic turn has the subject's result in test for assessment of static strength of leg muscles $(\beta=.35)$. Obtained results confirm that in learning and improving of skiing technique elements, where many turns are linked continuously, thigh and lower leg muscles' strength is necessary.

Parallel turn is the best representative of skiing technique in a wider corridor, which is mostly done by skiers while acquiring downhill skiing. Taking into account obtained results, it is possible to emphasize agility (frontal agility, $\beta=.22$; hexagon, $\beta=.32$ ) and static strength (squat endurance, $\beta=.27$ ) to contribute the most to parallel turn learning.

According to a definition, short turn is continuous association of short, incomplete parallel turns (Matković et al., 2004), and a skier will learn this element if he has developed agility. Subjects' ability to change direction of moving swiftly is assessed by three tests (side agility with step and close $(\beta=.26$ ), frontal agility $(\beta=.26)$, hexagon $(\beta=.34))$ which influence significantly short turn learning.

According to regression analysis results it is possible to note that hexagon test for agility assessment occurs systematically in learning all skiing technique elements, since the previous studies proved that, of all the motor abilities, explosive leg strength has the greatest influence on success of alpine ski competitors
(Bocco, 1997; Reid et al., 1997). So we can assume that agility is a motor ability which particularly contributes to skiing technique basics learning.

The previous studies arranged motor abilities according to their importance for competitor and recreational alpine skiers (Neumayr et al., 2003). The biggest influence on single motor ability development is possible to achieve by a proper training, doing specific focused exercises which will stimulate the rising of certain motor ability level. However, systematical skiing can also influence the motor abilities which are particularly important for skiing. But, since the recreational level skiers ski continuously for 6 , or 7 days, yearly we can assume that in such a short period of time it is not possible to significantly influence the development of the motor abilities important for skiing. For that reason, it is logical to recommend to skiers and those who will start skiing to have proper body preparation prior to skiing course. In order to have quality fitness preparation, skiers must definitely develop agility, static leg muscles strength and balance, because they have a great influence on efficacy of skiing learning. Underdevelopment of motor abilities undoubtedly has a certain negative influence on success while acquiring skiing technique elements. Focused exercises not done in ski field can influence development of the motor abilities which are particularly employed while skiing. Moreover, it is possible to influence the significant motor abilities important for skiing by doing specific body activities like rollerblading, besides preparation in specialized fitness centers. During rollerblading, a person performs almost the same movements as in performing short turn, and that is the reason why rollerblading is recommended while preparing for skiing (Roman, Miranda, Martinez, \& Viciana, 2009; Takahashi \& Yoneyama, 2001). Good fitness preparation influences the speed of skiing technique acquiring and minimizes the risk of possible injuries while skiing (Koehle, Loyd-Smith, \& Taunton, 2002).

Main components matrix was calculated by factor analysis based on subjects' marks for seven skiing technique elements.

One important factor is isolated $(\lambda=4.36)$ on the basis of calculated characteristic values using GK criteria. It is possible to assume that obtained factor represents skiing knowledge because it best explains the complete variance of seven elements of skiing technique $(62.26 \%)$.

Three tests for motor abilities assessment which influence a beginner's acquiring of skiing knowledge were selected in a variable obtained by factor analysis. As in skiing technique analyzed elements, contributi- 
on of test hexagon $(\beta=.35)$ is emphasized, and according to it subject's agility was estimated. Obtained results confirm the influence of agility on acquired skiing knowledge level.

\section{CONCLUSION}

Since the configuration of each ski field is different and snow conditions there are unique, at every moment a skier, while going down the slope, uses all motor abilities which together with acquired skiing knowledge take part in directing of skis. Of all the assessed motor abilities, agility has the greatest influence on ski beginners' acquiring of ski knowledge. Static leg strength also influences skiing technique learning, and balance is significantly important at the beginning of learning process while learning basic elements. Pedagogues, teachers and instructors should know ways and methods for teaching skiing. But when they teach specific ski movements they should respect motor abilities influence on that process. Therefore, recreational skiers or the future ones are recommended to have proper fitness motor preparation before going in ski fields.

\section{REFERENCES}

Benson, A. C., Torode, M. E., Fiatarone Singh, \& M. A. (2008). The effect of high - intensity progressive training on adiposity in children: a randomized controlled trial. International Journal of Obesity, 32, 1016-1027. doi:10.1038/ ijo.2008.5; PMid: 18283282

Bosco, C. (1997). Evoluation and planning condition training for alpine skiers. In E. Muller, H. Schwameder, E. Kornexl, and C. Raschner (Eds.), Science and skiing (pp. 229-250). London, UK: E\&FN Spoon.

Cigrovski, V., Matković, B., \& Matković, R. B. (2008a). Evaluation of objectivity and homogeneity of skiing knowledge grading process. In D. Milanović and F. Prot (Eds.), Proceeding book" 5 th International Scientific conference on Kinesiology" (pp. 513-517). Zagreb, HR: Kineziološki fakultet.

Cigrovski, V., Matković, B., \& Matković, R. B. (2008b). Koje motoričke sposobnosti doprinose boljem učenju elemenata skijaške tehnike [Motor skills that lead to better learning elements of ski technique]. In B. Maleš, Đ. Miletić, M. Kondrić, and M. Kvesić (Eds.), Proceeding book "3rd International Conference Contemporary Kinesiology" (pp. 54-59). Split, HR:
Faculty of Kinesiology University of Split, Faculty of Natural science, mathematics and education University of Mostar, Faculty of Sport University of Ljubljana.

Cigrovski, V., Bilić, Ž., Prlenda, N., \& Martinčević, I. (2010). The influence of explosive strength on learning of alpine skiing. In S. Simović (Ed), Proceeding book. "2nd International scientific conference Anthropological aspects of sports, physical education and recreation" (pp. 175-179). Banja Luka: Faculty of physical education and sports University of Banja Luka. doi: 10.5550/SP.2.2010.21

Cleland, V., Crawford, D., Baur, L. A., Hume, C., Timperio, A., \& Salmon, J. (2008). A prospective examination of children s time spent outdoors, objectively measured physical activity and overweight. International Journal of Obesity, 32(11), 1685-1693. doi: 10.1038/ijo.2008.171; PMid: 18852701

Dolenec, A., \& Žvan, M. (2001). Competitive success of junior female alpine skiers in light of certain chosen tests of co-ordination. Kinesiologia Slovenica, 7(1-2), 19-22.

Emeterio, C. A., \& González-Badillo, J. J. (2010). The physical and anthropometric profiles of adolescent alpine skiers and their relationship with sporting rank. J Strength Cond Res, 24(4), 1007-1019. doi: 10.1519/JSC.0b013e3181 cbabb5; PMid: 20300026

Gross, M., Lüthy, F., Kroell, J., Müller, E., Hoppeler, H., \& Vogt, M. (2010). Effects of eccentric cycle ergometry in alpine skiers. Int $\mathrm{J}$ Sports Med, 31(8), 572-578. doi: 10.1055/s-00301254082; PMid: 20464646

Grung, A., Krause, H., Siewers, M., Rieckert, H., \& Muller, M. J. (2000). Is TV viewing on index of physical activity and fitness in overweight and normal weight children? Public Health Nutrition, 4(6), 1245-1251.

Horterer, H. (2005). Carving skiing. Orthopade, 34(5), 426-458.

Högström, G.M., Pietilä, T., Nordström, P., \& Nordström, A. (2012). Body composition and performance: influence of sport and gender among adolescents. I Strength Cond Res, 26(7), 1799-1804. doi: 10.1519/JSC.0b013e318237 e8da; PMid: 22728941

Koehle, M. S., Loyd-Smith, R., \& Taunton, E. (2002). Alpine ski injuries and their prevention. Sports Med, 32(12), 785-793. doi: 10.2165/ 00007256-200232120-00003; PMid: 12238941

Kostelić A. (2005). Prikaz i analiza kondicijske pripreme Ivice i Janice Kostelic tijekom sportske karijere 
(razvoj i rezultati) [Presentation and analysis of traning Ivica and Janica Kostelic during sports career (development and results)]. Unpublished graduate work, University of Zagreb, Faculty of Kineziology.

Laguna, M., Ruiz, J. R., Lara, M. T., \& Aznar, S. (2012). Recommended levels of physical activity to avoid adiposity in Spanish children. Pediatr Obes, Epub ahead of print.

Maffiuletti, N. A., Jordan, K., Spring, H., Impellizzeri, F. M., Bizzini, M. (2009). Physiological profile of Swiss elite alpine skiers-a 10-year longitudinal comparison. In E. Müller, S. Lindinger, and T. Stoggl (Eds.), Science and skïng IV (pp. 365-373). Oxford, UK: Meyer and Meyer Sport.

Malliou, P., Amoutzas, K., Theodosiou, A., Gioftsidou, A., Mantis, K., Pylianidis, T., and Kioumourtzoglou, E. (2004). Proprioceptive training for learning downhill skiing. Percept Mot Skills, 99(1),149-203. doi: 10.2466/PMS.99.5. 149-154; doi: 10.2466/pms.99.1.149-154; doi: 10.2466/PMS.99.4.149-154; PMid: 15446640

Matković, B., Ferenčak, S., \& Žvan, M. (2004). Skijajmo rajedno [Go skiing together]. Zagreb, HR: Europapress holding i FERBOS inženjering.

Mišigoj-Duraković, M. (2008). Kinantropologijabiološki aspekti tjelesnog vje žbanja [Kinantropologybiological aspects of physical exercise]. Zagreb, HR: Kineziološki fakultet.
Neumayr, G., Hoertnagl, H., Pfister, R., Koller, A., Eibl, G., \& Raas, E. (2003). Physical and Physiological Factors Associated with Success in Professional Alpine Skiing. International Journal of Sports Medicine, 24(8), 571-575. doi: 10.1055/ s-2003-43270; PMid: 14598192

Oreb, G., Vlašić, J., Cigrovski, V., Prlenda, N., \& Radman, I. (2011). Relationship between rhythm and learning alpine skiing technique. In I.

Prskalo and D. Novak (Eds), Proceeding book "6th FIEP European congress Physical education in the 21 st century-pupils competencies" (pp. 640-646). Zagreb, HR: Hrvatski Kineziološki savez.

Reid, R. C., Johnson, S. C., Kipp, R. W., Albert, R.W., and White, A.T. (1997). Validity of sportspecific field tests fot elite and developing alpine ski racers. In E. Muller, H. Schwameder, E. Kornexl, and C. Raschner (Eds.), Science and skiing (pp. 285-296). London, UK: E\&FN Spoon.

Roman, B., Miranda, M. T., Martinez M., \& Viciana, J. (2009). Transfer from inline-skating to alpine skiing learning in physical education. In E. Müller, S. Lindinger, and T. Stoggl (Eds.), Science and skiing IV (pp. 430-438). Oxford, UK: Meyer and Meyer Sport.

Takahashi, M., \& Yoneyama, T. (2001). Basic ski teory and acceleration during ski turn. In E. Múller, S. Lindinger, and T. Stoggl (Eds.), Science and skiing IV (pp. 307-321). Hamburg, DE: Verlag Dr. Kovač.

Received: October 14, 2012

Revision received: December 16, 2012

Accepted: December 25, 2012

Correspondence to: Vjekoslav Cigrovski, PhD

Horvaćanski zavoj 15, 10000 Zagreb Croatia

E-mail: vjekoslav.cigrovski@kif.hr

Phone: 00385915442202 